\title{
DIREITO DO ESTADO, PROTEÇÃO SOCIAL E POPULAÇÃO LGBTQI+ Contribuições do pensamento de Maquiavel e Kant
}

State Law, Social Protection and LGBTQI+ Population: Contributions of the Thought of Maquiavel and Kant

\author{
Anabella Pavão, Neide Aparecida de Souza Lehfeld
}

Universidade Estadual Paulista, Brasil

\begin{tabular}{ll}
\hline KEY WORDS & ABSTRACT \\
\cline { 2 - 3 } $\begin{array}{l}\text { LGBTQI + Population } \\
\text { Social Protection }\end{array}$ & $\begin{array}{l}\text { This work reflects the importance of the State in the garantía of } \\
\text { Democratic State }\end{array}$ \\
Kant & Kant. The first Advocated a form of government that met the needs of the \\
Machiavelli & $\begin{array}{l}\text { importance of a constitutional charter that could regulate the relations } \\
\text { between state and society and between the people of it. A state that } \\
\text { claims to be democratic and secular should not distinguish gender and } \\
\text { sexuality to meet the needs of the people, buffering put this population at } \\
\text { risk to praise a conservative, old-fashioned and violent morality. }\end{array}$
\end{tabular}

PALAVRAS-CHAVE E

População LGBTQI+

Proteção social

Estado democrático de direito

Kant

Maquiavel

\section{RESUMO}

Este trabalho reflete a importância do Estado na garantía da proteção à população LGBTIQ a partir do pensamento de Maquiavel e Kant. $O$ primeiro defendia uma forma de governo que atendesse às necessidades do povo, sem perder sua autoridade; e o segundo argumentava a importância de uma carta constitucional que pudesse regular as relações entre estado e sociedade e entre as pessoas desta. Um Estado que se diz democrático e laico não deve fazer distintições de gênero e sexualidade para atender às necesidades do povo, tampoco colocar essa população em risco para enaltecer uma moral conservadora, antiquada e violenta.

Recebido: $30 / 04 / 2020$

Aceite: $10 / 11 / 2020$

\section{GLOBAL KNOWLEDGE}




\section{Introdução}

$\mathrm{U}$ $\mathrm{m}$ Estado que se apresenta democrático, possui o dever de propor e de efetivar ações de proteção social a todos os cidadãos, independentemente de qualquer circunstância. No século XVI, Maquiavel (2014) sinalizava que todo príncipe (trazendo a ideia também para os chefes de Estado de modo geral), deveria abster-se de valores pessoais, construindo um governo com valores que objetivassem o bem comum.

No século XVIII, Kant (2008; 2013), ao discutir a importância do Direito do Estado para regular a vida em sociedade, nos provoca a pensar a importância do respeito às diferenças e da proteção com vistas a garantir a tolerância, a não violência e tempos de paz.

Considerando a ideia de república democrática, de uma moral social e da proteção sem distinções, trazemos a discussão maquiaveliana e kantiana para o debate das políticas de proteção social à população LGBTQI+ (Lésbicas, Gays, Bissexuais, Transexuais, Transgêneros, Queers, Intersexuais...), tanto no cenário brasileiro, quanto no plano internacional. Várias nações, signatárias de acordos, tratados e convenções, vem inserindo em suas pautas, propostas de proteção à população LGBTQI+, que nem sempre são efetivadas.

Sabe-se ainda que países de culturas mais conservadoras rechaçam ou ainda criminalizam a diversidade sexual e de gênero, com penalidades que vão de pagamentos de multas, prisões por anos ou perpétua e pena de morte. Há países que legitimam a homossexualidade feminina e criminaliza a masculina, reforçando uma cultura patriarcal e machista, reificando e sexualizando a imagem da mulher.

À nossa frente, se apresenta um cenário carregado de contradições, de avanços e de desafios no que se refere à importância de os governantes compreenderem os seus papéis frente ao povo, repensando suas éticas e morais pessoais no espaço público que levarão às novas proposições e ações que materializem a proteção, segurança, respeito e dignidade à diversidade humana. Maquiavel e Kant contribuem, neste sentido, para pensarmos a democracia e a paz em Estados que deveriam respeitar e compreender a diversidade de seus povos.

Neste sentido, a partir de análise bibliográfica e documental, pelas vias da dialética crítica, objetiva-se neste trabalho, relacionar o pensamento clássico maquiaveliano e kantiano à proteção social, com enfoque nas demandas da população LGBTQI+, descortinando o cenário que se coloca no tempo presente.

\section{Proteção Social à população LGBTQI+: avanços e desafios no brasil}

O debate acerca da população LGBTQI+ emerge no Brasil na segunda metade do século $\mathrm{XX}$, quando os primeiros movimentos sociais ganham forma e iniciam o levante de bandeiras de luta, com demandas e discussões para se pensar a diversidade sexual e de gênero. A história nos revela que direitos são conquistados por meio de lutas e reivindicações que nós, da sociedade civil, fazemos perante os nossos representantes políticos que ocupam o poder do Estado por meio do voto democrático.

Em uma democracia, é condição sine qua non que as vozes das ruas sejam ouvidas e transformadas em proteção social por meio de políticas públicas. Nesta monta, o movimento LGBTQI+ brasileiro tem a sua efervescência no final da década de 1970, quando movimentos voltados pela reabertura democrática, contra a censura, repressão e violência da ditatura militar se acentuam no país.

Destacamos o protagonismo da luta homossexual masculina na década de 1970 e a inserção do movimento lésbico na década de 1980 como fundamentais para a ampliação e consolidação da luta LGBTQI+ no Brasil (Facchini, 2011). 0 estouro do movimento gay no Brasil possui influência direta das lutas sociais estadunidenses, tendo a revolta de Stonewall em junho de 1969 como o epicentro dos movimentos (Silva, 2009).

A partir deste período, Organizações da Sociedade Civil vão surgindo para alinhar em reivindicações por direitos, as demandas homossexuais instauradas nas primeiras mobilizações. As pioneiras na causa LGBTQI+, é o Grupo Somos de Afirmação Homossexual (São Paulo), voltado aos gays, e o Grupo Iamuricumá 
(Rio de Janeiro), direcionado ás mulheres lésbicas (Silva, 2019).

Tivemos ainda, segundo Silva (2019), na direção da difusão da informação e do conhecimento, dois jornais, perseguidos no período da ditadura militar, também direcionados aos públicos - gay e lésbico. São eles, respectivamente, o Lampião da Esquina (Rio de Janeiro, 1978-1981) e o Chanacomchana (São Paulo, 1981-1987).

Tanto as Organizações da Sociedade Civil, quanto os jornais foram fundamentais para a expansão da luta LGBTQI+ no Brasil. Várias pautas emergiram ao longo dos anos seguintes. A luta das mulheres lésbicas sendo acolhida no movimento feminista, a repulsa ao machismo e ao sexismo, principalmente por homens gays e por homens militantes de esquerda. 0 debate sobre a liberdade de expressão identitária e sexual, sobre o uso dos corpos, o sexo para o prazer e não só para a procriação, combate à patologização da homossexualidade e da Transexualidade, tratamento de saúde para as pessoas trans, contra o estereótipo da AIDS enquanto questão de saúde estritamente LGBT, e o combate à violência e criminalidade, hoje conhecida como LGBTfobia se acentuaram nos últimos anos do século XX.

Ao longo da década de 1990 e início dos anos 2000, a população travesti e transexual se inseriram no movimento, levantando as suas pautas, e as pessoas bissexuais também integram as lutas exigindo respeito e tolerância, lutando contra o estigma de que as pessoas bissexuais são indecisas.

Demais pautas, como união civil, adoção, nome social para pessoas transexuais, dentre outros, se formaram com maior propriedade já nos primeiros anos do século XXI. As demais siglas que hoje compõem o movimento LGBTQI+ se aproximaram no decorrer da segunda década do século XXI e, em espaços temporais cada vez mais curtos, novas siglas com novos sentidos vem surgindo para demonstrar a complexidade e a pluralidade da diversidade sexual e de gênero.

Conforme o movimento se expandiu, maiores as pressões por direitos sociais direcionados à população LGBTQI+. O princípio constitucional da igualdade perante a lei sem qualquer distinção, os direitos fundamentais e sociais, e ainda os direitos humanos são bases jurídicas nacionais e internacionais que correspondem à máxima necessidade de o Estado atender demandas específicas, materializando a igualdade com equidade e justiça social.

Para Immanuel Kant, o Estado democrático e republicano deve, pelo uso da razão de seus dirigentes, garantir por meio do Direito, a liberdade, a paz e a convivência humana no seu âmbito territorial e para além dele, pensando nas relações internacionais. 0 pensamento kantiano no provoca a pensar a importância do conceito de liberdade de escolha que todos nós temos por direito. A razão humana fundada na ética e na moral que respeita o pressuposto legal é a condição máxima que as pessoas devem possuir para fazerem suas escolhas.

Em um tempo anterior ao de Kant, Nicolau Maquiavel, ao escrever a obra "O Príncipe", reflete sobre a figura do Estado, defendo-o a partir do princípio da autonomia, principalmente de valores religiosos e valores particulares. 0 príncipe (o chefe de Estado) deve distanciar seus valores pessoais do seu poder na esfera pública, visando governar para todos. Isso não quer dizer que a religião deva ser extinta do Estado, só não pode servir de base fundante para ações frente ao povo (Maquiavel, 2014).

É o que hoje podemos associar ao ideal de Estado laico. Os componentes políticos do Estado possuem seus valores, suas crenças e religião, mas, ao assumirem o compromisso de representação dos interesses do povo, estes princípios individuais não deveriam se sobrepor à pluralidade social e popular. Defende-se que esta ideia se aplica ao debate sobre a diversidade sexual e de gênero na esteira da proteção social estatal.

Assumir-se e pertencer à comunidade LGBTQI+ não configura uma mera escolha, e sim, um processo de construção de cada um. Neste sentido, os postulados legais de um Estado que se afirma republicano e democrático, deve prezar legal, ética e moralmente pelo bem comum. E esse bem comum contempla o respeito, a tolerância e a proteção à diversidade sexual e de gênero, não permitindo que valores pessoais conservadores se sobressaiam à função protetiva do Estado de Direito, violando a liberdade individual de cada sujeito. 
Kant traz um conceito de liberdade determinado pelo direito, referindo-se a liberdade ao uso externo da liberdade de escolha. Já a liberdade, quando determinada pela moralidade, se refere tanto à liberdade externa quanto à liberdade interna de escolha, enquanto determinada pelo uso da razão. Desta forma a liberdade moral é exercida internamente, sendo livre o indivíduo para agir em conformidade com as leis que dá a si mesmo pelo uso de sua própria razão. Já a liberdade jurídica, a ser desenvolvida mais adiante, trata da faculdade de agir externamente sem que obstáculos sejam impostos ao exercício das ações (SCORZA, 2007, online).

A garantia da liberdade individual se efetiva por meio das leis que, segundo Kant (2013), configura-se no direito público. Direito por ser elaborado pelos representantes políticos ocupantes de espaços de poder no Estado e público porque depende das necessidades e da vontade pública. Em outras palavras, o Estado deve legislar a partir dos interesses da população, fazendo cumprir a sua vontade, sem cometer injustiças com ninguém. São os desafios da democracia em face às liberdades individuais e valores morais subjetivos que ainda se envolvem no debate acerca da vida pacífica em sociedade.

É à vontade do povo que cabe o poder legislativo. Ora, todo direito depende de leis. Uma lei pública é um ato de uma vontade pública da qual provém todo direito, que não pode cometer injustiça com ninguém. Para isso, a única vontade possível é a do povo reunido (Kant, 2013, p. 294).

No que tange os direitos LGBTQI+, a teoria contratualista kantiana fornece elementos para compreendermos a importância do Estado democrático na mediação dos interesses população, arbitrando nos confrontos morais que venham a desencadear violações e injustiças sociais. O contrato de convívio social, de liberdade e da paz entre cidadãos e nações deve partir dos princípios da justiça, da dignidade humana e da igualdade social.

Neste sentido, o Estado, como responsável por regular a vida social de modo a garantir o acesso a direitos essenciais para a vida humana, planeja, elabora, implementa, financia, executa (não de forma exclusiva) e fiscaliza as políticas sociais, que atendem diversas demandas da população. Demandas gerais da sociedade, como políticas habitacionais, de mobilidade urbana, assistência social, educação, cultura, saúde e segurança, como políticas setoriais, voltadas às especificidades de geração, raça/etnia, origem, expressão religiosa, deficiência, dentre outras demandas.

As políticas sociais e a formatação de padrões de proteção são desdobramentos e até mesmo respostas e formas de enfrentamento - em geral setorializadas e fragmentadas - às expressões multifacetadas da questão social no capitalismo, cujo fundamento se encontra nas relações de exploração do capital sobre o trabalho (Behring; Boschetti, 2007, p. 51).

O financiamento, a execução e a fiscalização de políticas públicas não é de exclusividade de um Estado orientado pelos ditames do neoliberalismo, que esta configuração chave do capitalismo contemporâneo defende um Estado mínimo em diversas responsabilidades, fortalecendo o mercado e atribuindo à sociedade civil, deveres frente a área social e suas múltiplas demandas.

Quando falamos em direitos LGBTQI+ no Brasil, destaca-se que, após 30 anos de mobilizações, o Estado começa a definir ações afirmativas e direitos sociais para esta parcela da população, ainda com vários entraves morais e conservadores que se infiltram no Estado Democrático de Direito através de políticos retrógrados, que lutam para conservar valores e costumes que sempre foram violados por estas mesmas pessoas, consideradas "de bem", atrasando o progresso de uma nação de quase 520 anos que, desde a invasão portuguesa até hoje, preza-se pelo antiquado, atraso, pela invisibilidade das minorias sociais e pelo poder central do homem branco, rico, heterossexual e cisgênero.

São tempos de barbárie, de avanço do conservadorismo, no qual "pessoas de bem" prestam um desserviço em face à dignidade da pessoa humana e ao amor entre as pessoas em nome de uma família tradicional decadente, de uma moral cristã e bons costumes hipocritamente construídos e que servem de 
fachada para a manutenção de um nome e status social, ocultando um cotidiano secreto de desejos, fetiches e vontades que muitas vezes ultrapassam a imaginação e se concretizam no plano real.

A sociedade conservadora do século XXI não só se auto reprime e oprime uns aos outros como também contribuem para as repressões e opressões de uma diversidade humana cada vez mais expressiva e presente no cotidiano. A luta é por liberdade, mas não a liberdade enviesada pelo neoliberalismo, onde a sua começa quando acaba a do outro. Liberdade na compreensão da teoria social crítica de Karl Marx. Liberdade que emancipa humanamente todos nós, sujeitos, libertando-nos de todas as amarras do capitalismo conservador, dominador, explorador e opressor.

Diante o cenário de preconceitos, intolerâncias, fundamentalismos, falência da laicidade do Estado, violências de diversas naturezas, é importante destacar avanços e também as necessidades e as possibilidades de resistências. Conquistamos direitos e almejamos ainda mais. É a contribuição da Comunidade LGBTIQ+ na luta pela emancipação humana. Cabe destacar que estas conquistas só foram possíveis, pois, a população LGBTIQ+ organizouse politicamente durante as décadas de 1970 a 1990, fortalecendo-a a partir dos primeiros anos do século XXI.

Uma nação que se diz democrática e republicana, deveria nem cogitar a hipótese de violar direitos da população pelo fato de serem diferentes do padrão heterossexual e cisgênero historicamente imposto pelos valores morais e religiosos.

A concepção de república conota o poder que povo possui para escolher e enviar representantes para a esfera pública e a democracia segue o mesmo sentido, o qual toda a população tem direito e dever de participar da vida política de seu território, seja no sufrágio, seja na ocupação de cargos no interior do Estado.

Ao mesmo tempo, de forma contraditória, observamos cada vez mais governos que dizem representativos, mas que, à tomar posse após as eleições, estes mesmos representantes viram as costas para os interesses gerais do povo, defendendo somente interesses privados. Além disso, temos ainda experiências devastadoras de governantes eleitos democraticamente que, com poder em mãos, agem contra as liberdades e dignidade da população.

Um rápido exemplo, é o próprio caso brasileiro, a partir da eleição de Jair Bolsonaro para a presidência da república em outubro de 2018. Enquanto deputado e depois, presidenciável, Bolsonaro propagou diversas vezes discursos de ódio contra minorias sociais, rasgou uma cópia do Plano Nacional LGBT, incitou a violência contra esta população e, eleito, vem por meio de seus ministros, fortalecendo uma onda de retrocessos frente às conquistas já alcançadas. A informação mais recente e assustadora foi o compromisso firmado pelo novo Procurador Geral da República Augusto Aras com o setor evangélico (protestante), principalmente contra a união civil LGBT garantida por regulamentação jurídica desde 2013.

Vivemos um período em que o Estado, que se diz laico, mas que, a cada medida governamental e a cada discurso, se aproxima mais de um aparelho público religioso fundamentalista, de base protestante neopentecostal ${ }^{1}$, que viola direitos e segrega parte da população das responsabilidades de um governo e de um Estado Democrático de Direito.

$\mathrm{Na}$ contracorrente, ainda que pese muitas críticas, as pautas políticas LGBTIQs têm sido garantidas por ações judiciais, com decisões históricas pelo Supremo Tribunal Federal, dentre várias, a mais recente a comparação da LGBTfobia ao crime de racismo, criminalizando assim, a violência contra esta população.

Voltando à discussão acerca da conquista de direitos, conforme já exposto, esta inaugura-se

\footnotetext{
${ }^{1}$ Igrejas neopentecostais compõem a terceira onda do pentecostalismo, compreendendo em uma vertente do protestantismo evangélico de cunho carismático. As pregações se desenvolvem no sentido da unção ao Espírito Santo pelas mãos, combate à demônios, uso de outros idiomas de ordem bíblica, associam problemas de saúde, infelicidade ou fracasso à possessão demoníaca. Esta doutrina atrai mais de 250 milhões de pessoas no mundo todo (Porto, 2010, online). Também é conhecida pela ampla extorsão econômica frente aos seus fiéis, como se a contribuição financeira fosse fundante para a salvação eterna, além dos frequentes discursos de ódio contra o que eles chamam de natureza divina. Neste ponto, entra a perseguição e violência contra LGBTs em nome de "Deus".
} 
em 2002 através da pressão dos movimentos feministas e de demais setores da sociedade, quando foi criada a Secretaria de Estado dos Direitos da Mulher, e em 2003, no governo de Luiz Inácio Lula da Silva, temos a criação da Secretaria Especial de Políticas para as Mulheres (SPM), vinculada ao gabinete da presidência, tendo a Secretária status de Ministro. A SPM passa a abrigar em sua estrutura o CNDM, agora como órgão consultivo e não deliberativo.

Em 2004, quando elaborado o Plano Plurianual (2004-2007), foi estabelecido no âmbito do Programa de Direitos Humanos a Elaboração do Plano de Combate à Discriminação contra Homossexuais. Diante dessa realidade, a Secretaria Especial de Direitos Humanos (SEDH) da Presidência da República lança no mesmo ano o Programa Brasil sem Homofobia. Este programa "é uma das bases fundamentais para ampliação e fortalecimento do exercício da cidadania no Brasil. Um verdadeiro marco histórico na luta pelo direito à dignidade e pelo respeito à diferença. É o reflexo da consolidação de avanços políticos, sociais e legais tão duramente conquistados" (Ministério da Saúde, 2004, p. 6). Deste período para o tempo presente, foram várias políticas instituídas com novos direitos para esta população, os quais, vamos sintetizar neste momento.

2002 - Programa Nacional dos Direitos Humanos (PNDH-2). Segundo Silva (2009), enquanto programa governamental brasileiro com inspiração na Carta de Viena de 1993, estabelece diretrizes e princípios para o combate às violações de direitos humanos, fortalecendoos enquanto responsabilidade estatal frente ao povo. Não há menções à população LGBT nesta primeira versão, mas a metodologia de discussão, construção e publicação estimulou os movimentos sociais LGBTs da época a defenderem a sua inserção no documento.

2004 - Programa Brasil Sem Homofobia, conforme já exposto anteriormente.

2005 - Plano Nacional de Políticas para as Mulheres. 0 governo Lula reconhece a importância da luta pela igualdade e equidade nas relações de gênero, bem como o combate à violência contra a mulher, fortalecendo sua cidadania e sua condição de sujeito direitos. 0 reconhecimento governamental se deu sob as bases dos movimentos sociais feministas e de debates em várias esferas da vida social que se uniram à sensibilidade governamental do então presidente Lula. Este Plano traça estratégias e orientações para a implementação de políticas públicas de proteção e valorização das mulheres.

2006 - Lei Maria da Penha (Lei 11340/2006). Após anos de luta para responsabilizar criminalmente as várias violências sofridas por Maria da Penha pelo seu companheiro, a justiça reconhece a violência contra a mulher como uma particularidade que o Estado deve se atentar para projetar ações de proteção social no campo da violência. Esta conquista só foi possível porque Maria da Penha chegou a recorrer na Corte Interamericana de Direitos Humanos já que o Estado não tomava providências quanto ao caso. A Lei, que leva o seu nome, preconiza as diretrizes, princípios e procedimentos para o atendimento e proteção às mulheres vítimas de violência. A lei abarca a violência contra mulheres cisgênero, transexuais, heterossexuais e lésbicas. Há muitos desafios para a concreta efetivação desta lei, mas avançamos após a sua publicação.

2007 - Plano Integrado de Enfrentamento à Feminização da Epidemia de AIDS. Este Plano elaborado pela Secretaria Especial de Políticas para Mulheres e pelo Ministério da Saúde, numa vertente de gênero, cultura, economia e violência reconheceu a expansão da epidemia de AIDS no público feminino, principalmente por contaminações via violência sexual ou contaminação de homens em suas companheiras, devido às relações extraconjugais. 0 documento traça estratégias de prevenção e tratamento para reduzir este processo contaminação em mulheres, que se encontra em índices elevados no período.

2007 - Plano Nacional de Enfrentamento da Epidemia de AIDS e das DSTs ${ }^{2}$ Entre Gays, HSH e Travestis. A partir de levantamento de informações do Ministério da Saúde, constatou-se

\footnotetext{
${ }^{2}$ Atualmente, a partir de mudanças de nomenclatura pela Organização das Nações Unidas para o Combate à AIDS (UNAIDS) e Organização Mundial de Saúde, as DSTs (Doenças Sexualmente Transmissíveis) passaram a ser denominadas ISTs (Infecções Sexualmente Transmissíveis). A mudança acompanha o avanço da medicina que reelabora reflexões acerca destas infecções, suas manifestações e possibilidades de tratamentos (Silva, 2019).
} 
que a epidemia de DSTs e AIDS ainda se encontravam em maior número entre a população LGBT. Desta forma, o Estado brasileiro assume enquanto política de saúde pública o compromisso em agir na prevenção e tratamento para maior proteção a este público, buscando garantir a dignidade e qualidade de vida.

2008 - Segundo Plano Nacional de Políticas para Mulheres. Após a II Conferência Nacional de Políticas para Mulheres, com ampla participação da sociedade civil em paridade com o Estado, discutiu-se novas possibilidades de promoção da justiça e igualdade social nas relações de gênero, atualizando a primeira versão do Plano para uma mais coerente aos avanços e desafios nas lutas das mulheres brasileiras.

2009 - Plano Nacional da Cidadania e dos Direitos Humanos LGBT. Em um esforço coletivo entre governo e sociedade civil, o Plano Nacional LGBT traça diretrizes e estratégias para a garantia de direitos fundamentais e sociais para este público, reconhecendo-os enquanto cidadãos. Parece óbvio este reconhecimento, mas vivemos em uma conjuntura moralista e conservadora que ainda tenta reduzir a concepção de ser humano frente à todos que se consideram diferentes dos padrões morais estabelecidos. Por mais que o Plano não se efetivou da forma esperada, ele deixa provocações acerca da cidadania LGBT e acesso a políticas públicas e direitos de proteção social.

2009 - Programa Nacional dos Direitos Humanos (PNDH-3). Aprovado por meio do Decreto no. 7037/2009, ele atualiza o Plano de 2002, buscando fortalecer as garantias de direitos humanos sob os eixos - político, participativo, econômico, segurança, universalidade de direitos, trabalho, renda, combate à pobreza e desigualdades, dentre outros eixos. A diferença ante ao Plano anterior é que o PNDH-3 reconhece a população LGBT como demandatária de ações de proteção social para garantia e preservação de direitos de cidadania.

2010 - Política Nacional de Saúde Integral LGBT. Inaugurado em 2010 e atualizado em 2013, esta política traça o processo histórico de atendimento de saúde à população LGBT. Compreende-se que as ações de saúde sempre se pautaram nas ISTs e AIDS. Porém, enquanto humanos com diversas necessidades de cuidados, o Estado a partir de debates em sua esfera e com a sociedade civil compreende que a saúde integral LGBT avança na garantia do atendimento universal e de qualidade à esta população que apresenta novas demandas cotidianas, como as pessoas transexuais nos modernos tratamentos para redesignação de gênero. Assim, o Plano apresenta a compreensão da diversidade sexual e de gênero e como a saúde pública nas esferas federal, estadual e municipal devem atuar em face desta população. Trata-se de um documento informativo e reflexivo. Em 2013, o Plano Nacional e o Plano Operativo foram unificados num único documento, atualizado e com novas propostas, e em 2017, o Plano Operativo foi atualizado novamente.

2011 - Plano Operativo da Política Nacional de Saúde Integral LGBT. Este documento publicado complementa o texto descrito acima apresentando as estratégias e diretrizes para a efetivação da Política Nacional.

2013 - Redefinição e ampliação do processo transexualizador no SUS (Sistema Único de Saúde). A portaria que regula este processo data de 2008, mas só foi qualificada e normatizada com maior rigor em 2013, quando definiu-se parâmetros e procedimentos por meio de protocolos para atender com qualidade este processo, que é complexo e de mudança radical na vida das pessoas transexuais. Atualmente, a saúde pública brasileira atua na terapia hormonal para a mudança dos traços corporais de mulheres e homens transexuais, acompanhamento psicológico e psiquiátrico para o cuidado à saúde mental destas pessoas e a cirurgia de redesignação de gênero que altera a região dos órgãos genitais biológicos.

No quesito educação, ainda estamos muito aquém de uma política educacional que atenda as demandas da diversidade sexual e de gênero. Movimentos conservadores, principalmente de base religiosa católica e evangélica usam de forças para proibir qualquer aproximação deste debate em face de crianças e adolescentes com a justificativa de sociedade e Estado estarem atentando contra a moral ao pregar uma "ideologia de gênero" que influenciaria as gerações mais jovens a converterem-se à 
sexualidade não heterossexual e não cisgênero. Uma falácia que se transforma em verdade e atrasa ainda mais a educação voltada ao respeito e tolerância.

Ao mesmo tempo, movimentos mais resistentes vêm utilizando do espaço escolar ou de outras políticas públicas, como de assistência social, esporte, cultura e lazer para levar o debate, a reflexão e o trabalho social para elevar o pensamento das gerações mais jovens, instigando-os a crescerem respeitando a diversidade e as diferenças que se estabelecem entre as pessoas. No tocante à previdência social, receita federal e poder judiciário, obtivemos avanços no reconhecimento da união civil, adoção, pensão por morte, dependência e declaração de imposto de renda, dentre outros direitos que destacaremos a seguir.

2005 - Primeiro processo de adoção deferido para casal homossexual. Pela primeira vez na história das adoções no Brasil, um casal homoafetivo conseguiu, mediante processo judicial, o direito de serem pais adotivos. Por mais que o Estatuto da Criança e do Adolescente de 1990 e o Código Civil de 2002 não apresentavam impedimentos legais para a adoção por casais homoafetivos, os indeferimentos eram constantes devido aos valores morais conservadores que se sobrepunham às fundamentações jurídicas. Todavia, um casal da cidade de Catanduva, estado de São Paulo lutou na justiça para o obterem o direito de serem pais (Silva, 2007). 0 processo de adoção reconheceu, a priori o direito à paternidade por apenas um dos homens, já que, na época, a união civil LGBT ainda não era reconhecida, tampouco permitida. Após a decisão, o casal entrou na justiça para o reconhecimento da paternidade pelos dois homens. Após análise jurídica e jurisprudência do Direito Internacional, o casal consegue o reconhecimento das duas paternidades no registro de nascimento da criança. Este marco histórico na adoção brasileira abre precedentes para novas possibilidades.

2006 - PLC 122/2006. O Projeto de Lei Constitucional aberto pela Câmara dos Deputados propunha alterações na Lei que versa o crime de racismo, no Código Penal de 1940 e na Consolidação das Leis do Trabalho de 1943 para incluir dentre os crimes de preconceito e discriminação, a penalidade por estes crimes contra a população LGBT. O projeto foi discutido internamente na Câmara, com baixa participação da população. Movimentos políticos conservadores ganharam força e o projeto não avançou, sendo encerrado em 2014. A Câmara retomou a discussão em 2017 e em 2019 com novas propostas de debates, mas esta retomada não impediu o Supremo Tribunal Federal (STF) de se posicionar e deliberar sobre a pauta. Até a escrita deste texto, a Câmara dos Deputados não definiu nenhuma proposição sobre a temática.

2007 - Direitos previdenciários LGBT. As ações neste direito emergiram no Brasil em 2000 por meio de Ação Civil Pública promovida pelo Ministério Público Federal contra o Instituto Nacional do Seguro Nacional (INSS). Esta ação se dá após denúncia da Organização da Sociedade Civil (OSC) denominada Nuances, de Porto Alegre, estado do Rio Grande do Sul. A denúncia versava sobre extensão dos direitos de pensão por morte e auxílio reclusão (por privação de liberdade de um/a dos/as companheiros/as) (Irineu, 2009). 0 INSS recorreu da decisão tanto em instância estadual, quanto nacional, chegando o processo até ao STF. O Supremo Tribunal reconhece, com base no princípio da igualdade de direitos, que casais formados por LGBTs também deve acessar direitos previdenciários, desde que comprovem requisitos para o reconhecimento do direito. Estes requisitos também se aplicam a casais heteroafetivos. Reparem que o preconceito e discriminação por orientação sexual e identidade de gênero se reflete na esfera pública, na qual a moral conservadora por vezes fala mais alto que os princípios e direitos constitucionais e de direitos humanos.

Em 2001, o INSS publica uma Instrução Normativa que garante o direito à pensão por morte e auxílio reclusão a casais compostos por pessoas do mesmo sexo. Em 2007 o debate retoma em um momento de reforma das leis previdenciárias, para aprimorar esta conquista, fortalecendo a discussão sobre a desigualdade de gênero e sexualidade e como esta reflete na proteção à LGBTs. Obviamente que este fortalecimento ainda permeia os conflitos e os interesses daqueles que defendem a moral subjetiva cristã ao invés do direito concreto de proteção. 
Como a composição do Estado Brasileiro não é monolítica, observamos disputas acirradas em debates e processos judiciais que, quando deliberadas positivamente, modernizam o direito brasileiro e a proteção social a grupos sociais historicamente invisíveis e marginalizados do campo dos direitos fundamentais, sociais e humanos (Nour, 2003). Esta perspectiva retoma o pensamento contratualista kantiano que discute a importância de uma Constituição de Estado que regulamentará a vida social entre todos os sujeitos de um determinado território. Este debate também vai de encontro a Maquiavel (2014), quando afirma que o Estado corresponde a um campo de correlação de forças, o qual, quem o ocupa, busca legitimidade e poder pelas vias da opressão e, ao povo, cabe a luta pela liberdade em suas relações sociais e na vida individual.

Ousando uma associação de ideias, o preconceito e a intolerância pela diversidade de expressões de gênero e sexualidade na sociedade e a ausência de fundamentação legal que impeça as discriminações levaria o Estado à ideia de Kant de estado de natureza, onde inexiste leis de proteção que acentuam a insegurança social e a incapacidade do Estado em gerir as violências.

Quando o Estado, por meio de suas instituições jurídicas, executivas e legislativas debatem, conflitam e convergem, mesmo quando não há unanimidade, favorável à novas prerrogativas de proteção social, concretizam pelas vias do pensamento racional, jurídico e social as possibilidades de garantir a dignidade e a qualidade de vida de um determinado povo.

2010 - Plano de Saúde privado a casais LGBTs. A Súmula Normativa no 12 , da Agência Nacional de Saúde Suplementar (ANS) reconhece enquanto companheiro/a de beneficiário titula de plano privado de assistência à saúde, as pessoas do mesmo sexo e de sexo oposto, estendendo assim, a cobertura de dependência em plano de saúde à população LGBT com reconhecida união civil ou estável. A decisão da ANS se pauta nos princípios constitucionais da igualdade, da proibição de discriminações, da dignidade da pessoa humana, da liberdade e da segurança jurídica, reconhecendo no campo da saúde privada, a população LGBT, sujeitos dos mesmos direitos das demais pessoas.
2011 - Reconhecimento da União Estável entre casais do mesmo sexo. Em votação histórica pelo STF, define-se, seguindo os princípios constitucionais, que toda união afetiva entre pessoas do mesmo sexo, se houver desejo de regulamentá-la conforme os preceitos legais, deve ser considerada como união estável ${ }^{3}$ (Supremo Tribunal Federal, 2011). União estável é diferente do casamento civil e este, até 2013, ainda não era legítimo no país. Esta decisão fortalece o pensamento sociológico das múltiplas configurações de famílias, entrando neste rol, as famílias homoafetivas, hoje chamadas de famílias homotransparentais, reconhecendo o direito das pessoas transexuais em constituírem família com seus companheiros ou companheiras.

2011 - Dependentes LGBTs em declaração do Imposto de Renda. Após o Supremo Tribunal Federal reconhecer a união estável de casais do mesmo sexo, a Receita Federal do Brasil passa a permitir que casais LGBT, que comprovem estarem em união estável, declarem conjuntamente seus impostos de renda. A declaração é única, alinhando rendimentos e gastos do casal (Laporta, 2018). Para isso, a Receita Federal exige que o casal comprove união por 5 anos ou que tenham filhos adotivos em conjunto. Estes critérios também se aplicam aos casais heterossexuais em união estável.

2011 - Módulo LGBT no Disque 100. O Disque 100 é uma ferramenta governamental onde qualquer pessoa de todas as partes do Brasil pode ligar para realizar denúncias de violências contra vários segmentos populacionais suscetíveis à maiores riscos de violências.

0 Disque 100 recebe, analisa e encaminha denúncias de violações de direitos humanos relacionadas aos seguintes grupos e/ou temas: crianças e adolescentes; pessoas idosas; pessoas com deficiência; pessoas em restrição de liberdade; população LGBT; população em situação de rua; discriminação étnica ou racial; tráfico de pessoas; trabalho escravo; terra e conflitos agrários; moradia e conflitos urbanos; violência contra ciganos, quilombolas, indígenas

\footnotetext{
3 União estável é um contrato estabelecido entre duas pessoas que vivem em relação de convivência duradoura e estável, que reconhece a formação de um núcleo familiar. De acordo com o Código Civil de 2002, não é delimitado um tempo mínimo de convivência para o casal ser reconhecido em união estável.
} 
e outras comunidades tradicionais; violência policial; violência contra comunicadores e jornalistas; violência contra migrantes e refugiados (Ministério dos Direitos Humanos, 2018, online). Até 2011 a população LGBT não era coberta neste campo, passando, por decisão governamental, a sua inclusão, visibilizando centenas de denúncias por ano.

Somente em 2018, mais de 1600 denúncias confirmaram mais de 2000 violações de direitos à população LGBTQI+. Em cada denúncia pode ser relatada mais de uma violação. "Em 2018, as denúncias somaram 1.685 casos, que resultaram em 2.879 violações. Destas, $70,56 \%$ são referentes à discriminação, seguida por violência psicológica - que consiste em xingamentos, injúria, hostilização, humilhação, entre outros (com 47,95\%) - violência física $(27,48 \%$ ) e violência institucional (11,51\%)" (Ministério da Mulher, da Família e dos Direitos Humanos, 2019, online).

Neste quesito, as instituições que compõem o Estado brasileiro ainda são falhas em concretizar uma coesão entre a violência real ocorrida diariamente contra esta população e os dados oficiais registrados para a implementação de ações mais eficazes e efetivas no campo da segurança pública. Dados atualizados pelo então Ministério dos Direitos Humanos em 2018 (hoje Ministério da Mulher, da Família e dos Direitos Humanos) e divulgados por Sobrinho (2019), confirmam que, a cada 16 horas, um LGBTQI+ é assassinado no Brasil.

2011 - STF compreende que não há nada que impeça casais de pessoas do mesmo sexo de adotar crianças. Considerando a abertura legal inaugurada em 2005 para a adoção por casais homoafetivos, em 2011, o STF legitima a pauta após deferir novo processo de adoção que havia sido recusado em instância jurídica do estado do Paraná. A partir desta decisão, os ministros do Supremo entendem que a Constituição Federal não distingue a instituição familiar por sexo e gênero, deliberando pelo reconhecimento da família homoafetiva e da legitimidade em adotar filhos (Instituto Brasileiro de Direito de Família, 2015). A adoção considera que as famílias pretendentes comprovem condições afetivas e materiais de cuidar com dignidade e proteção qualquer criança que se torne membro efetivo destas via processo de adoção. Novamente, observamos conflitos morais preconceituosos mascarados de ilegalidade e inconstitucionalidade para tentar barrar avanços na proteção de direitos LGBTQI+. No entanto, a decisão foi unânime, facilitando o caminho para casais homotransparentais participarem de processos de adoções. Destaca-se que o preconceito não foi vencido, mas as decisões judiciais têm caminhado para a democratização e respeito à entidade familiar configurada por LGBTQIs+.

2013 - União Civil homoafetiva. Até 2013, casais homoafetivos que desejassem contrair o casamento civil precisavam entrar com ação judicial para a garantia deste direito até então, ilegítimo no Brasil. Mediante as conquistas de direitos listadas até o referido ano, o Conselho Nacional de Justiça (CNJ) determinou por meio da Resolução 175/2013 a obrigatoriedade de todos os cartórios realizarem o casamento para pessoas do mesmo sexo. Segundo Bandeira (2017), mesmo com a determinação do CNJ, muitos cartórios ainda se recusam a garantir este direito. A autora ainda destaca que o próprio Ministério Público de alguns estados também se opõe à medida. Estima-se que entre 2013 a 2017 foram realizados no Brasil mais de 15 mil casamentos homoafetivos. Uma grande conquista, sem dúvida. Reparem que a resistência em reconhecer a diversidade de gênero e sexualidade é um grande obstáculo para que o Estado Brasileiro possa se legitimar como democrático, de direito e laico.

2014 - Permitido o uso do nome social no Exame Nacional do Ensino Médio (ENEM). O ENEM é um exame que todos os estudantes que estão finalizando o ensino médio realizam para avaliação de desempenho. 0 exame existe desde 1998 e favorece por meio da nota final, a inclusão dela nos vestibulares para ingresso ao ensino superior nas universidades públicas e privadas. Algumas universidades já aboliram o vestibular e inserem alunas e alunos via nota do ENEM. Neste sentido, para candidatas e candidatos transexuais e travestis, passa a ser garantido o uso de nome social. A solicitação deve ser realizada por telefone durante 0 período de inscrição. N formulário de inscrição, registra-se o nome civil (Aquino, 2014). 
O nome social é o nome escolhido pela pessoa travesti ou transexual que mais contemple com a sua identidade e expressão de gênero. Não é necessário que o nome social esteja incluído em algum documento oficial. A auto declaração da pessoa já garante que a legitimidade e o reconhecimento de seu novo nome. Até o início de 2017, qualquer retificação de nome civil para o social nos documentos oficiais brasileiros era realizada mediante decisão judicial.

2016 - Registro de crianças nascidas por técnica de reprodução assistida. Esta técnica favorece o direito de engravidar por mulheres que apresentam determinadas dificuldades. Em alguns casos, a reprodução assistida tem se estendido a casais impossibilitados de gerarem filhos pelo caminho natural e ainda por casais homoafetivos que desejam filhos consanguíneos. Neste sentido, o Provimento no. 52/2016 do CNJ estabelece que casais heteroafetivos e homoafetivos que tiverem filhos por meio da reprodução assistida possam registrá-los com os nomes dos dois pais, das duas mães, do pai e da mãe na certidão de nascimento. Não há a necessidade de autorização judicial. A comprovação da dupla paternidade, dupla maternidade ou paternidade e maternidade é o suficiente para o registro civil da criança.

2016 - Uso de nome social em todas as instituições da esfera pública federal. Pela primeira na história dos direitos de cidadania brasileiros, nenhuma lei apresentava o conceito e o reconhecimento do nome social e da identidade de gênero. A partir de 2016, a esfera federal garante por meio do Decreto no. 8727/2016 o uso de nome social em todas as instâncias públicas geridas pelo governo federal. 0 direito se aplica a cidadãos que acessam serviços e atendimentos, servidores, estudantes, professores, enfim, todas as pessoas que, de algum modo, estão inseridas nestes espaços.

Quanto ao conceito legal de nome social, o Decreto apresenta que é "designação pela qual a pessoa travesti ou transexual se identifica e é socialmente reconhecida" e a identidade de gênero é "dimensão da identidade de uma pessoa que diz respeito à forma como se relaciona com as representações de masculinidade e feminilidade e como isso se traduz em sua prática social, sem guardar relação necessária com o sexo atribuído no nascimento" (Decreto, 2016). No Brasil, o nome civil é aquele cujos pais ou responsáveis escolhem para registrar a criança logo após o seu nascimento. É o nome atribuído que será a referência para a criança em todos os espaços que ela ocupar desde a infância até a velhice. No caso da redesignação de gênero, a pessoa transexual pode retificar seu nome civil para o social, compatibilizando a identidade nominal à identidade de gênero.

2017 - Uso do nome social no Cadastro de Pessoa Física (CPF) da Receita Federal. O reconhecimento de uso do nome social para pessoas transexuais e travestis se legitima no âmbito da Receita Federal por meio da Instrução Normativa $\mathrm{n}$. . 1718/2017. A Receita faz a inclusão de nome social no CPF, ou seja, passa a constar no documento o nome social em destaque e o nome civil logo abaixo e demais informações como data de nascimento e o número de registro documental. Mesmo aparecendo os dois nomes, pelo princípio da liberdade e da dignidade humana, deve prevalecer sempre o nome social. A pessoa transexual deve comparecer a uma agência da Receita Federal e solicitar a inclusão por auto declaração. 0 documento fica pronto imediatamente.

2017 - Inclusão do nome social - Carteira de Trabalho da Previdência Social (CTPS), Certidão de Militar, Número de Identificação Social (NIS), Cadastro Nacional de Saúde (CNS). Avançando no cumprimento do Decreto 8727/2016, as instâncias - previdenciária, saúde pública e militar passam a reconhecer o uso de nome social para a emissão da carteira de trabalho, cartão SUS (este é utilizado pela cidadã e cidadão em todo atendimento na rede de saúde pública do país), no alistamento e reservista militar (no caso de homens transexuais). São direitos que estão se consolidando nestas esferas do Estado brasileiro. No cartão SUS, o uso de nome social era autorizado desde 2014, se legitima legalmente a partir de 2017.

2017 - Inclusão de nome social na Carteira Nacional de Habilitação (CNH). O Departamento Nacional de Trânsito (DENATRAN) inicia diálogos com os Departamentos Estaduais de Trânsito (DETRANs) para adaptação do atual modelo da CNH para a inclusão de nome social 
para motoristas transexuais e travestis legalmente habilitados a dirigirem. 0 processo ainda está em fase de adaptação nos estados brasileiros (Faustino, 2017).

2018 - Decreto que regulamenta a validade do Registro Geral (RG) autoriza a inclusão de nome social. A Carteira de Identidade ou RG é um documento expedido pelos órgãos de segurança dos estados brasileiros. Na solicitação, registrase os dados do cidadão e cidadã requerente, tirase foto e coleta-se as impressões digitais da pessoa. É um documento obrigatório em todo território nacional. A última legislação que tratava deste documento era de 1983. Em 2018, no governo Michel Temer, este decreto sofre alterações. Publica-se assim, o Decreto Federal 9278, de 5 de fevereiro de 2018, que passa a autorizar a inclusão de nome social no RG.

Além do nome social, a nova versão contempla a inserção de todas as informações documentais da pessoa - número de registro de certidão de nascimento, dados da carteira nacional de habilitação, CPF, título de eleitor e identificação social da previdência social, carteira de trabalho, certidão militar e indicativo de deficiências para pessoas assim identificadas (Decreto, 2018). A proposta é unificar os documentos, mas todos os demais, continuam possuindo validade e importância. A pessoa trans deve comparecer às instâncias autorizadas a emitirem os RGs, solicitar a nova versão do documento com a inclusão de nome por auto declaração.

2018 - Portaria do Tribunal Superior Eleitoral autoriza a emissão dos títulos de eleitores com nome social. A Portaria Conjunta TSE $\mathrm{n}^{\circ}$ 1, de 17 de abril de 2018 regulamenta a alteração de nome civil para o nome social para as eleitoras e eleitores transexuais legalmente habilitados para o exercício do direito ao voto. A pessoa transexual deve agendar o atendimento via internet, comparecer com os documentos pessoais na data marcada e fazer a solicitação de alteração. 0 documento é emitido de forma imediata e passa a constar no título de eleitor apenas o nome social. Quando da emissão de declaração de quitação da situação eleitoral, isto é, o documento que atesta que a pessoa está em dia com as obrigações eleitorais, o nome social e o nome civil aparecem conjuntamente, prevalecendo o direito ao primeiro.

2018 - Retificação de nome civil para o nome social na Certidão de Nascimento. Até junho de 2018, toda pessoa trans que apresentasse a demanda de alterar seu nome no registro civil de nascimento, deveria entrar com pedido de ação judicial. A decisão judicial se baseava em um laudo emitido por médico especializado que atestava a transexualidade da pessoa. Em outras palavras, quem dizia se éramos ou não transexuais era a medicina, e a partir dela que a justiça poderia legitimar este reconhecimento por meio dos documentos pessoais que refletem a nossa condição de cidadãs e cidadãos de direitos. A partir de junho, o CNJ publica o Provimento no. 73/2018 que autoriza, via auto declaração a retificação de nome na certidão de nascimento. A pessoa transexual precisa comparecer a um Cartório de Registro Civil para solicitar a retificação. Para isso, será necessário comprovar informações judiciais, criminais, sociais, pagar uma taxa para a emissão. Não é mais necessária ação judicial, tampouco laudo médico, até porque, a transexualidade que nunca foi uma patologia, deixa de ser assim considerada também em 2018 pela Organização Mundial de Saúde (OMS).

2018 - Autorização de uso de nome social nos Tribunais de Justiça. No tocante aos serviços judiciários, o CNJ publica a Resolução no. 270, de $11 / 12 / 2018$, que dispõe sobre o uso do nome social pelas pessoas trans, travestis e transexuais usuárias dos serviços judiciários, membros, servidores, magistrados, estagiários e trabalhadores terceirizados dos tribunais brasileiros. Ou seja, independente da condição de acesso aos serviços de justiça, está assegurado o uso de nome social.

2019 - Equiparação da violência LGBTQI+ ao crime de racismo. Considerando que o Congresso Nacional não legislou a pauta da LGBTfobia até o momento por omissão, o STF, por meio de ação civil pública impetrada por Organizações da Sociedade Civil LGBT e partidos políticos simpatizantes à causa desta população, julgou por meses a possibilidade de equiparar os crimes cometidos contra LGBTQIs+ ao crime de racismo, sendo este legítimo no país desde 1989. Aos 13 de junho de 2019, por 8 oito votos favoráveis e 3 
contrários, o Supremo Tribunal reconhece a LGBTfobia como crime (Barifouse, 2019). Em que pese críticas à segurança do povo negro que vive violências cotidianas pela questão étnica/racial mesmo com uma legislação que versa o contrário, o texto legal fundamenta os direitos de proteção e segurança, que passam a se estender à população LGBTQI+. A decisão histórica do Supremo não exime o Congresso Nacional da responsabilidade de legislar sobre a pauta e tomar providências para a contenção, redução e extinção dos crimes de ódio contra esta população. Nesta decisão, prevaleceu a participação da população que, ocupando os espaços da esfera pública fez-se presente, exigindo das instâncias governamentais, ações efetivas para fundamentar a luta pela segurança, dignidade, liberdade e direito à vida da população LGBTQI+.

A participação popular se fundamenta nas bases do republicanismo e da democracia, que, em tese, valoriza a voz do povo, ecoando-a nos interiores do Estado. Sem participação não há conquista, sem pressão popular, não há proteção social. Mesmo vivendo em uma nação republicana, democrática e laica, com uma constituição que regula a vida social, política, econômica, cultural e religiosa da população, atribuindo responsabilidades ao Estado e Sociedade, ainda precisamos dos movimentos sociais e políticos para garantirem o cumprimento da carta constituição, que deveria dignificar a população por meio do respeito às liberdades, agindo contra a intolerância e a violência.

\section{Concluindo}

O presente trabalho ora concluído, ousa associar dois pensadores de tempos tão distantes e distintos à uma temática contemporânea, complexa e cada vez mais presente nos espaços sociais, jurídicos e acadêmicos. Maquiavel, pensador do século XVI e Kant, do século XVIII não debateram questões de sexualidade e gênero, até porque, em seus tempos históricos, era inadmissível discutir qualquer assunto que não fosse voltado à natureza divina cristã.

Entretanto, quando eles falavam em Estado, república, democracia, eles defendiam o princípio da liberdade por meio da regulação contratualista entre Estado e sociedade, isto é, um governo legítimo, escolhido pelo povo, deve legislar para o povo e para si. O Estado social e político, superaria o estado de natureza, selvagem e antissocial através de uma constituição republicana e democrática que preze pela justiça, igualdade, liberdade e dignidade.

São nestes princípios, que inserimos a pauta LGBTQI+, compreendendo a diversidade sexual e de gênero como natural do ser humano, com um legado histórico a ser constantemente resgatado, visando fortalecer direitos de cidadania à esta população que, historicamente sofre as mais diversas e nefastas formas de violência, cometida por vários protagonistas que disputam poder: Estado, Igreja e setores da sociedade.

Desta forma, relacionamos Maquiavel (2014) e Kant $(2008 ; 2013)$ no desafio de trazer à luz do pensamento político, jurídico e protetivo, a importância dos postulados republicanos e democráticos se concretizarem de fato em todas as esferas da vida social, respeitando a diversidade que compõe a civilização humana, consolidando a proteção, liberdade e direitos à população LGBTQI+ de todas as partes do globo.

Por mais que destacamos aqui, os avanços no Brasil, não podemos esquecer que, em alguns países, ser diferente é crime, passível de morte. Neste ponto que deixamos a última provocação: como condenar e ceifar o direito à vida de pessoas que são particularmente diferentes, diversos na natureza humana e complexos conforme a história avança. Os valores e princípios morais devem acompanhar o desenvolvimento da civilização humana.

Assim, defender a proteção à comunidade LGBTQI+ é defender a liberdade, a dignidade, os direitos humanos, de cidadania, a justiça social, a igualdade e a equidade, todos princípios e valores relacionados à democracia e a república. 


\section{Referências}

Aquino, Y. (2014). Travestis e transexuais poderão usar nome social no Enem. Sítio Agência Brasil. Recuperado de http://agenciabrasil.ebc.com.br/educacao/noticia/2014-05/travestis-etransexuais-poderao-usar-nome-social-no-enem

Barifouse, R. (2019). STF aprova a criminalização da homofobia. BBC News Brasil. Recuperado de https://www.bbc.com/portuguese/brasil-47206924

Behring, E. R. and Boschetti, I. (2007). Política Social: fundamentos e história (Coleção Biblioteca Básica de Serviço Social, 3a ed.). São Paulo: Cortez.

Constituição da República Federativa do Brasil de 1988. Recuperado de http://www.planalto.gov.br/ccivil_03/Constituicao/Constituicao.htm

Decreto n. 4229, de 13 de maio de 2002. Dispõe sobre o Programa Nacional de Direitos Humanos - PNDH, instituído pelo Decreto no 1.904, de 13 de maio de 1996, e dá outras providências. Recuperado de http://www.planalto.gov.br/ccivil_03/decreto/2002/D4229.htm

Decreto $n$. 7037, de 21 de dezembro de 2009. Aprova o Programa Nacional de Direitos Humanos - PNDH-3 e dá outras providências. Recuperado de http://www.planalto.gov.br/ccivil_03/_Ato20072010/2009/Decreto/D7037.htm\#art7

Decreto n. 8727, de 28 de abril de 2016. Dispõe sobre o uso do nome social e o reconhecimento da identidade de gênero de pessoas travestis e transexuais no âmbito da administração pública federal direta, autárquica e fundacional. Recuperado de http://www.planalto.gov.br/ccivil_03/_Ato2015-2018/2016/Decreto/D8727.htm

Decreto $n$. 9278, de 5 de fevereiro de 2018. Regulamenta a Lei $\mathrm{n}^{-}$7.116, de 29 de agosto de 1983, que assegura validade nacional às Carteiras de Identidade e regula sua expedição. Recuperado de http://www.planalto.gov.br/ccivil_03/_Ato2015-2018/2018/Decreto/D9278.htm

Fachinni, R. (2011). Histórico da luta LGBT no Brasil. In: Conselho Regional de Psicologia. Psicologia e diversidade sexual. (Cadernos Temáticos 11, Cap. 1, pp. 10-19). São Paulo: CRPSP. Recuperado de http://www.crpsp.org.br/portal/comunicacao/cadernos_tematicos/11/frames/caderno_tematico 11.pdf

Faustino, E. (2017). Detran acerta nome social na CNH de motoristas trans e travestis. Observatório IG. Recuperado de https://observatoriog.bol.uol.com.br/noticias/2017/06/detran-acerta-nomesocial-na-cnh-de-motoristas-trans-e-travestis

Instituto Brasileiro de Direito de Família (2015). STF reconhece que casal gay adotar sem restrições de idade sexo. $e$ Recuperado de http://www.ibdfam.org.br/noticias/5580/STF+reconhece+direito+de+casal+gay++adotar+sem $+\mathrm{r}$ estrições+de+idade+e+sexo

Instrução Normativa RFB n. 1718, de 18 de julho de 2017. Altera a Instrução Normativa RFB no 1.548, de 13 de fevereiro de 2015, que dispõe sobre o Cadastro de Pessoas Físicas (CPF). Recuperado de http://normas.receita.fazenda.gov.br/sijut2consulta/link.action?visao=anotado\&idAto $=84588$

Irineu, B. A. (2009). A política de previdência social e os direitos LGBT no Brasil (Dissertação de Mestrado). Faculdade de Ciências Sociais, Universidade Federal de Goiás, Goiânia, GO, Brasil. Recuperado de https://pos-sociologia.cienciassociais.ufg.br/up/109/o/Dissertação_-_Sociologia_-_Bruna_Irineu_Final.pdf

Kant, I. (2008). A paz perpétua. Covilhã: Universidade da Beira Interior. Recuperado de https://www.marxists.org/portugues/kant/1795/mes/paz.pdf

- (2013). A metafísica dos costumes. Petrópolis: Vozes; Bragança Paulista: Editora Universitária São Francisco. Recuperado de http://cabana-on.com/Ler/wp-content/uploads/2017/09/Metafisicados-Costumes-Immanuel-Kant.pdf

Laporta, T. (2013). Casal gay pode fazer declaração conjunta no Imposto de Renda. Sítio IG - Brasil Econômico. Recuperado de: https://economia.ig.com.br/financas/impostoderenda/2013-0405/casais-gays-podem-declarar-parceiros-como-dependentes-no-ir.html 
Lei n. 11340, de 7 de agosto de 2006. Cria mecanismos para coibir a violência doméstica e familiar contra a mulher, nos termos do $\S 8^{\circ}$ do art. 226 da Constituição Federal, da Convenção sobre a Eliminação de Todas as Formas de Discriminação contra as Mulheres e da Convenção Interamericana para Prevenir, Punir e Erradicar a Violência contra a Mulher; dispõe sobre a criação dos Juizados de Violência Doméstica e Familiar contra a Mulher; altera o Código de Processo Penal, o Código Penal e a Lei de Execução Penal; e dá outras providências. Recuperado de http://www.planalto.gov.br/ccivil_03/_Ato2004-2006/2006/Lei/L11340.htm

Maquiavel, N. (2014). $O$ Príncipe. Rio de Janeiro: Nova Fronteira.

Ministério da Mulher, da Família e dos Direitos Humanos (2019). Disque 100 registra quase três mil violações contra a população LGBT. Recuperado de https://www.mdh.gov.br/todas-asnoticias/2019/junho/disque-100-registra-quase-tres-mil-violacoes-contra-a-populacao-lgbt

Ministério da Saúde and Conselho Nacional de Combate à Discriminação (2004). Programa Brasil sem Homofobia: Programa de combate à violência e à discriminação contra GLTB e promoção da cidadania homossexual. Brasília: Ministério da Saúde.

- (2007). Plano Integrado de Enfrentamento à Feminização da Epidemia de AIDS. Brasília: Ministério da Saúde. Recuperado de http://bvsms.saude.gov.br/bvs/publicacoes/plano_feminizacao_final.pdf

- (2007). Plano Nacional de Enfrentamento da Epidemia de AIDS e das DSTs Entre Gays, HSH e Travestis. Brasília: Ministério da Saúde. Recuperado de http://bvsms.saude.gov.br/bvs/publicacoes/plano_enfrentamento_epidemia_aids_hsh.pdf

- (2010). Plano Nacional de Saúde Integral de Lésbicas, Gays, Bissexuais, Travestis e Transexuais. Brasília: Ministério da Saúde. $\quad$ Recuperado de http://bvsms.saude.gov.br/bvs/publicacoes/politica_nacional_saude_lesbicas_gays.pdf

- (2011). Plano Operativo de Saúde Integral de Lésbicas, Gays, Bissexuais, Travestis e Transexuais. Brasília: Ministério da Saúde.

- (2013). Plano Nacional de Saúde Integral de Lésbicas, Gays, Bissexuais, Travestis e Transexuais. Brasília: Ministério da Saúde. Recuperado de http://bvsms.saude.gov.br/bvs/publicacoes/politica_nacional_saude_lesbicas_gays.pdf

- (2017). II Plano Operativo de Saúde Integral de Lésbicas, Gays, Bissexuais, Travestis e Transexuais. Brasília: Ministério da Saúde. Recuperado de http://bvsms.saude.gov.br/bvs/saudelegis/cit/2017/res0026_27_10_2017.html

- (2017). Processo Transexualizador no SUS. Recuperado de http://www.saude.gov.br/atencaoespecializada-e-hospitalar/especialidades/processo-transexualizador-no-sus

Ministério dos Direitos Humanos (2018). Disque 100: Oficina Nacional aborda políticas públicas para a população LGBT. Recuperado de https://www.mdh.gov.br/todas-asnoticias/2018/novembro/disque-100-oficina-nacional-aborda-politicas-publicas-para-apopulacao-lgbt

Nour, S. (2003) Os cosmopolitas: Kant e os "temas kantianos em Relações Internacionais". Contexto Internacional, 25(1), 7-46.

Portaria Conjunta TSE n. 1, de 17 de abril de 2018. Regulamenta a inclusão do nome social no cadastro eleitoral, prevista na Resolução-TSE 23.562, de 22.3.2018. Recuperado de http://www.tse.jus.br/legislacao-tse/prtc/2018/PRTC00012018TSE.html

Porto, G. Neopentecostalismo. (2010). Sítio Infoescola Recuperado de https://www.infoescola.com/religiao/neopentecostalismo/

Projeto de Lei da Câmara dos Deputados n. 122, de 2006. Altera a Lei no 7.716, de 5 de janeiro de 1989, que define os crimes resultantes de preconceito de raça ou de cor, dá nova redação ao § 3 do art. 140 do Decreto-Lei no 2.848, de 7 de dezembro de 1940 - Código Penal, e ao art. 5o da Consolidação das Leis do Trabalho, aprovada pelo Decreto-Lei no 5.452, de $1^{\circ}$ o de maio de 1943, e dá outras providências. Recuperado de https://www25.senado.leg.br/web/atividade/materias//materia/79604 
Provimento n. 52, de 2016. Dispõe sobre o registro de nascimento e emissão da respectiva certidão dos filhos havidos por reprodução assistida. Recuperado de https://www.cnj.jus.br/busca-atosadm?documento $=3109$

Provimento n. 73, de 2018. Dispõe sobre a averbação da alteração do prenome e do gênero nos assentos de nascimento e casamento de pessoa transgênero no Registro Civil das Pessoas Naturais (RCPN). Recuperado de https://www.cnj.jus.br/busca-atos-adm?documento=3503

Resolução CNJ n. 175, de 14 de maio de 2013. Dispõe sobre a habilitação, celebração de casamento civil, ou de conversão de união estável em casamento, entre pessoas de mesmo sexo. Recuperado de http://www.cnj.jus.br/images/imprensa/resolução_n_175.pdf

Resolução CNJ n. 270, de 11 de dezembro de 2018. Dispõe sobre o uso do nome social pelas pessoas trans, travestis e transexuais usuárias dos serviços judiciários, membros, servidores, estagiários e trabalhadores terceirizados dos tribunais brasileiros. Recuperado de http://www.cnj.jus.br/busca-atos-adm?documento=3666

Scorza, F. A. T. (2007). O Estado na obra de Kant. Recuperado de https://jus.com.br/artigos/9580/oestado-na-obra-de-kant

Secretaria Especial de Direitos Humanos. Plano Nacional da Cidadania e dos Direitos Humanos LGBT. Brasília: Presidência da República e Secretaria Especial de Direitos Humanos. Recuperado de http://bibliotecadigital.planejamento.gov.br/xmlui/bitstream/handle/123456789/1006/planolg bt.pdf?sequence $=1 \&$ isAllowed $=y$

Secretaria Especial de Políticas para Mulheres (2005). Plano Nacional de Políticas para as Mulheres. Brasília: Secretaria Especial de Políticas para Mulheres. Recuperado de http://bvsms.saude.gov.br/bvs/publicacoes/pnpm_compacta.pdf

- and Conselho Nacional dos Direitos da Mulher (2008). II Plano Nacional de Políticas para as Mulheres. Brasília: Presidência da República e Secretaria Especial de Políticas para Mulheres. Recuperado de http://portal.mec.gov.br/dmdocuments/planonacional_politicamulheres.pdf

Silva, A. P. (2019). Direitos Sociais para a diversidade sexual e de gênero: Estado e Proteção Social à comunidade LGBTQIA. Texto de trabalho. Acesso Restrito.

Silva, T. R. (2007, outubro). Adoção por casais homossexuais: uma nova constituição de família na sociedade do século XXI. Anais do Congresso Brasileiro de Assistentes Sociais. Foz do Iguaçu, PR, Brasil, 12. CD room.

Silva, T. R. (2009). As múltiplas expressões da diversidade sexual e políticas públicas: construção da homossociabilidade LGBT no espaço social contemporâneo (Monografia de Conclusão de Curso). Faculdade de Serviço Social, Universidade de Ribeirão Preto, Ribeirão Preto, SP, Brasil.

Súmula Normativa n. 12 (2010). Para fins de aplicação à legislação de saúde suplementar, entende-se por companheiro de beneficiário titular de plano privado de assistência à saúde pessoa do sexo oposto ou do mesmo sexo. Recuperado de http://www.ans.gov.br/component/legislacao/?view=legislacao\&task=TextoLei\&format=raw\&id $=\mathrm{NzA}=$

Supremo Tribunal Federal (2011). Supremo reconhece união homoafetiva. STF Notícias. Recuperado de http://www.stf.jus.br/portal/cms/verNoticiaDetalhe.asp?idConteudo=178931 